\title{
Evaluation of Serum HDL and LDL levels in Type II Diabetes Mellitus
}

\author{
KR Joshi, ${ }^{a}$ KK Hiremath, ${ }^{a}$ SP Gupta ${ }^{a}$
}

\begin{abstract}
:
Introduction: Diabetes mellitus is a type of metabolic disorder characterized by hyperglycemia resulting from defect in insulin secretion, insulin action or both. This study intended to compare High Density Lipoprotein Cholesterol (HDL) and Low Density Lipoprotein Cholesterol (LDL) profile between type II diabetic and non-diabetic subjects and also find the correlation between HDL and LDL cholesterol in type II diabetic. Methods: The study was conducted on 100 total subjects out of which experimental group with 50 subjects of known Type II Diabetes mellitus and control group with 50 subjects. Results: The result of the present study suggests that fasting blood sugar and LDL cholesterol levels were increased but HDL cholesterol level was reduced in type II diabetic subjects when compared to controls. Conclusion: The estimation of HDL cholesterol and LDL cholesterol in type II diabetes mellitus is very useful as it may serve as a useful parameter to monitor the prognosis of the patient.
\end{abstract}

Keywords: type II diabetes $\bullet$ serum HDL $・$ LDL $・$ Cholesterol

\section{INTRODUCTION:}

Diabetes mellitus is a group of metabolic disorder characterized by hyperglycemia resulting from defect in insulin secretion, insulin action or both. ${ }^{1}$ Diabetes mellitus is characterized by either the absence of insulin that is Insulin Dependent Diabetes Mellitus (IDDM) type I or which is insensitive to the insulin that is Non-Insulin Dependent Diabetes Mellitus (NIDDM) or Type II. It is a complex disease where the carbohydrate and fat metabolism is impaired. ${ }^{2}$ Type II diabetes is associated with a marked increased risk of cardiovascular disease (CVD). Individuals with diabetes has an absolute risk of major coronary events similar to that of non-

a - Lecturer

Department of Biochemistry,

Padmashree Institute of Medical Lab. Technology,

Nagarbhavi Circle, Bangalore, India

Corresponding Author:

Dr. KR Joshi

e-mail: drkrjoshi@jlmc.edu.np

How to cite this article:

Joshi KR, Heremath KK, Gupta SP. Evaluation of serum HDL and

LDL levels in type II diabetes mellitus. Journal of Lumbini Medical

College. 2013;1(1):21-4. doi:10.22502/jlmc.v1i1.7. diabetic individuals with established coronary heart disease (CHD). ${ }^{3}$ LDL Cholesterol is the main lipid marker in cardiovascular risk estimation and the principle therapeutic target in diabetic subjects. ${ }^{4}$ High Density Lipoprotein (HDL) cholesterol is inversely correlated with cardiovascular events in all major epidemiological studies. Strategies have demonstrated that increased HDL cholesterol is associated with decreased cardiovascular risk in high risk individuals such as patients with type II diabetes. ${ }^{5}$ Abnormal lipid profile is more common in diabetics and get aggravated with poor glycemic control. Thus, the measurement of lipid profile is needed to investigate how their lipid metabolism especially HDL and LDL cholesterol is affected by diabetes. Also, the correlation of HDL cholesterol and LDL cholesterol in diabetics and non-diabetics was observed in this study. ${ }^{6}$ High level of LDL cholesterol and low HDL cholesterol may be due to obesity, increased calorie intake and a lack of muscular exercise in the patients of diabetes mellitus. ${ }^{2}$ Hence this study was designed where in HDL and LDL cholesterol levels have been correlated for diabetic and non-diabetic healthy subjects. ${ }^{7}$ 


\section{METHODS:}

A Case-Control study with 50 controls as non-diabetic cases and 50 cases as Diabetic patients was undertaken to study the HDL and LDL profile. The present study was carried out on total 100 subjects, which were divided into two groupsexperimental group which consisted of 50 subjects with known Type II Diabetes mellitus and control group which consisted of 50 healthy non- diabetic subjects with no present and past family history of diabetes mellitus. A total 50 type II diabetic subjects were recruited in the study, among which 35 were males and 15 were females in the age group of 40 70 years. Non-insulin dependent diabetes mellitus patients were being treated by diet alone or diet combined with oral hypoglycemic agents.

\section{RESULTS:}

The study was a case control study where fasting plasma glucose, serum HDL cholesterol, serum LDL cholesterol was estimated, compared and correlated in type II diabetic and non-diabetic subjects.

Table 1 and Table 2 show that the mean age studied in type-II diabetes mellitus patients was 54.34 yrs $(S D=8.48)$ and 53.40 yrs $(S D=7.95)$ in control subjects showing a suggestive significance $p=0.57$. Whereas the percentage of gender study showed the control group with 54\% male and $46 \%$ female when compared to case group male $68 \%$ and $32 \%$ female showing a non significant difference, $p=0.15$. Hence, suggesting that the study comprised of equal distribution of age group and gender.

Table 3 shows that fasting plasma glucose and serum LDL cholesterol levels were elevated in case group with mean $164.56 \mathrm{mg}(S D=51.17)$ and $121.42 \mathrm{mg}(S D=27.89)$ respectively when compared to the control group mean of $95.48 \mathrm{mg}(S D=10.09)$ and $103.64 \mathrm{mg}(S D=30.67)$ respectively. A strong significance $(p<0.001$ and $p=0.003)$ was found between case and control group's mean fasting plasma glucose and serum LDL cholesterol levels respectively. Whereas HDL cholesterol levels had fall in case group mean (39.22 \pm 7.96$)$ when compared to the control group $(44.06 \pm 10.57)$ showing a $p$ value of 0.011 .

Table 4 shows a comparison of HDL cholesterol in case and control. A strong significance is observed when compared with HDL cholesterol level <40mg/dl $(p<0.001)$ and HDL cholesterol level is $40-60 \mathrm{mg} / \mathrm{dl}(p<0.001)$. A significant lower incidence of HDL cholesterol levels is seen in case group than in controls (76\% verses $32 \%$ respectively where $\mathrm{HDL}<40.0 \mathrm{mg} / \mathrm{dl}$ and $22 \%$ verses $60 \%$ respectively where HDL is in between $40-60 \mathrm{mg} /$ $\mathrm{dl}, p<0.001)$. Whereas there was no significant in control and case group where HDL cholesterol levels where $>60 \mathrm{mg} / \mathrm{dl}(p=0.36)$.

Table 1: Age distribution

\begin{tabular}{|l|c|c|c|c|}
\hline \multirow{2}{*}{ Age in years } & \multicolumn{2}{|c|}{ Controls } & \multicolumn{2}{c|}{ Cases } \\
\cline { 2 - 5 } & No & $\%$ & No & $\%$ \\
\hline $41-50$ & 22 & 44.0 & 18 & 36.0 \\
\hline $51-60$ & 19 & 38.0 & 20 & 40.0 \\
\hline $61-70$ & 9 & 18.0 & 12 & 24.0 \\
\hline Total & 50 & 100.0 & 50 & 100.0 \\
\hline Mean \pm SD & \multicolumn{2}{|c|}{$53.40 \pm 7.95$} & \multicolumn{2}{c|}{$54.34 \pm 8.48$} \\
\hline
\end{tabular}

Samples are age matched with $p=0.569$

Table 2: Gender distribution

\begin{tabular}{|l|c|c|c|c|}
\hline \multirow{2}{*}{ Gender } & \multicolumn{2}{|c|}{ Controls } & \multicolumn{2}{c|}{ Cases } \\
\cline { 2 - 5 } & No & $\%$ & No & $\%$ \\
\hline Male & 27 & 54.0 & 34 & 68.0 \\
\hline Female & 23 & 46.0 & 16 & 32.0 \\
\hline Total & 50 & 100.0 & 50 & 100.0 \\
\hline
\end{tabular}

Table 4: Comparison of HDL

\begin{tabular}{|l|c|c|c|}
\hline \multicolumn{1}{|c|}{ HDL } & $\begin{array}{c}\text { Controls } \\
(\mathrm{n}=50)\end{array}$ & $\begin{array}{c}\text { Cases } \\
(\mathrm{n}=50)\end{array}$ & P value \\
\hline $\begin{array}{l}\text { Low } \\
(<40.0 \mathrm{mg} / \mathrm{dl})\end{array}$ & $16(32.0 \%)$ & $38(76.0 \%)$ & $<0.001^{* *}$ \\
\hline $\begin{array}{l}\text { Borderline } \\
(40-60 \mathrm{mg} / \mathrm{dl})\end{array}$ & $30(60.0 \%)$ & $11(22.0 \%)$ & $<0.001^{* *}$ \\
\hline $\begin{array}{l}\text { High } \\
(>60 \mathrm{mg} / \mathrm{dl})\end{array}$ & $4(8.0 \%)$ & $1(2.0 \%)$ & 0.362 \\
\hline
\end{tabular}

Table 3: Comparison of blood parameters

\begin{tabular}{|l|c|c|c|}
\hline \multicolumn{1}{|c|}{ Variables } & Controls & Cases & P value \\
\hline FBS $(\mathrm{mg} / \mathrm{dl})$ & $95.48 \pm 10.09$ & $164.56 \pm 51.17$ & $<0.001^{* *}$ \\
\hline $\mathrm{HDL}(\mathrm{mg} / \mathrm{dl})$ & $44.06 \pm 10.57$ & $39.22 \pm 7.96$ & $0.011^{*}$ \\
\hline $\mathrm{LDL}(\mathrm{mg} / \mathrm{dl})$ & $103.64 \pm 30.67$ & $121.42 \pm 27.89$ & $0.003^{* *}$ \\
\hline
\end{tabular}


Table 5 shows a significant negative correlation between HDL and LDL cholesterol ( $r$ $=-0.221$ ) where in the LDL cholesterol levels are elevated whereas HDL cholesterol is reduced in case groups compared to control group which is significant.

Table 5: Comparison of $L D L$

\begin{tabular}{|l|c|c|c|}
\hline \multicolumn{1}{|c|}{ LDL } & $\begin{array}{c}\text { Controls } \\
(\mathrm{n}=50)\end{array}$ & $\begin{array}{c}\text { Cases } \\
(\mathrm{n}=50)\end{array}$ & P value \\
\hline $\begin{array}{l}\text { Optimal } \\
(<100 \mathrm{mg} / \mathrm{dl})\end{array}$ & $\begin{array}{c}22 \\
(44.0 \%)\end{array}$ & $\begin{array}{c}12 \\
(24.0 \%)\end{array}$ & $0.057+$ \\
\hline $\begin{array}{l}\text { Near optimal } \\
(100-129 \mathrm{mg} / \mathrm{dl})\end{array}$ & $\begin{array}{c}18 \\
(36.0 \%)\end{array}$ & $\begin{array}{c}19 \\
(38.0 \%)\end{array}$ & 1.000 \\
\hline $\begin{array}{l}\text { Borderline high } \\
(130-159 \mathrm{mg} / \mathrm{dl})\end{array}$ & $\begin{array}{c}8 \\
(16.0 \%)\end{array}$ & $\begin{array}{c}12 \\
(24.0 \%)\end{array}$ & 0.454 \\
\hline $\begin{array}{l}\text { High } \\
(160-189 \mathrm{mg} / \mathrm{dl})\end{array}$ & $\begin{array}{c}7 \\
(4.0 \%)\end{array}$ & $\begin{array}{c}7 \\
(14.0 \%)\end{array}$ & 0.160 \\
\hline $\begin{array}{l}\text { Very high } \\
(\geq 190 \mathrm{mg} / \mathrm{dl})\end{array}$ & 0 & 0 & - \\
\hline
\end{tabular}

\section{DISCUSSION:}

The result obtained from present study has confirmed that the previous observations of an increased LDL and decreased HDL cholesterol levels in diabetic patients. ${ }^{8}$ Type II diabetes mellitus is chronic degenerative disease of epidemic proportion and is one of the major challenges to public health. ${ }^{9}$ The mean age studied in type II diabetes mellitus patients control subjects was 54.34 yes $(S D=8.48)$ 53.40 yrs $(S D=7.95)$ respectively. There appears to be no sex predilection for type II diabetes mellitus according to this study. This is similar to other studies that reported no significant differences in the prevalence of type II diabetes mellitus between males and females. ${ }^{10}$ The fasting blood glucose levels are elevated significantly $(p<0.001)$ in NIDDM patients, when compared to the controls which is consistent with earlier reports by other researchers. ${ }^{11-13}$ The HDL cholesterol was low in type II patients when compared to control. The decrease was found to be moderately significant $(p=0.01)$ in type II patients. Similar studies have been reported by Harno K. ${ }^{14}$ The reduction of HDL cholesterol in type II diabetic patients may be due to the increased activity of hepatic lipase, which plays an important role in HDL metabolism. ${ }^{14}$ However controversial studies also have been reported where no significant change in HDL cholesterol levels in diabetic patients reported. ${ }^{15} \mathrm{HDL}$ cholesterol concentration are strongly and independently related to coronary artery disease, but the relationship is inverse; a low HDL cholesterol being an important predictor of coronary heart disease and whereas high levels of HDL cholesterol is protecting against coronary heart disease. A possible explanation for these finding is the role played by HDL cholesterol in reverse cholesterol transport as an acceptor of cellular free cholesterol. ${ }^{16}$ The LDL cholesterol is elevated significantly $(p<0.003)$ in type I diabetic patients when compared to control. However, there was a small correlation between LDL cholesterol in type II diabetic patients. The above findings are consistent with the observations by other researchers. ${ }^{17}$

Metabolic reasons for lower HDL levels have not been fully documented. Decreased synthesis of HDL has been found in one small study. ${ }^{18}$ Schmitt JK suggested that LDL uptake by fibroblasts may be impaired in type II diabetics. This may have led to increase in LDL cholesterol and decrease in HDL cholesterol in type II diabetics.II This is much similar to our study showing a negative correlation between LDL and HDL cholesterol $(r=-0.221)$ in diabetics.

\section{CONCLUSION:}

The estimation of HDL cholesterol and LDL cholesterol in type II diabetes mellitus is very useful as it may serve as a useful parameter to monitor the prognosis of the patient. The detection of risk factor in the early stage of the disease will help the patients to improve and reduce the morbidity rate. The result of the present study suggests that fasting blood sugar and LDL cholesterol levels were found to be increased in type II diabetic subjects when compared to controls. The HDL cholesterol level was reduced statistically in diabetics when compared to controls. A significant negative correlation was observed between HDL and LDL cholesterol in diabetic subject.

Confilict of interest declared: None

Financial support: None 


\section{REFERENCES:}

1. Process S, Delrange E, Vander Burghs TV. Minor alteration in thyroid function test associated with Diabetes mellitus and obesity in outpatient without known thyroid illness. Acta Clin Big. 2001.

2. Suryawanshi NP, Bhutey AK, Nagdeote AN. Study of lipid peroxide and lipid profile in diabetes mellitus. Ind J Clin Biochem. 2006;21:126-30.

3. Wagner AM, Sanchez-quesada JL, Perez A, Rigla M. Inaccuracy of calculated LDL-cholesterol in type-2 diabetes: consequences for patient risk classification and therapeutic decisions. Clin Chem. 2000;46:1830-2.

4. Solano MP, Goldberg RB. Lipid management in type-2 diabetes. Am Diabetes Assoc Clin Diabetes. 2006;24:27-2.

5. Nieuw drop M, Vergeer M, Bisoendial RJ. Reconstituted HDL infusion restores endothelial function in patients with type 2 diabetes mellitus. Diabetologia. 2008;51:1081- 4.

6. Ugwa CE, Ezeanyika LUS, Daikwo MA. Lipid profile of a population of diabetic patients attending Nigerian National Petrolium Corporation Clinic, Abuja. Afr J Biochem Res. 2009;3:066-9.

7. Kumar A, Tewari P, Sahoo SS. Prevalence of insulin resistance in first degree relatives of type-2 Diabetes Mellitus Patients: A Prospective Study in north Indian Popula_on" Ind J Clin Biochem 2005;20:10-7.

8. David M. Initial management of glycemia in type-2 diabetes mellitus. N Eng J Med. 2002;347:1342-9.

9. Bhalla K, Shukla R, Gupta VP, Pugazhenthi S, Prabhu KM. Glycated protein and serum lipid profile in complicated and uncomplicated NIDDM patient. Ind J Clin Biochem. 1995; 10:57-66.

10. Idogun ES, Unuigbe EI, Ogunuro PS, Akinola OT. Assessment of serum lipids in Nigerians with type - 2 diabetes mellitus complications. Pak J Med Sci. 2007;23:708-2.
11. Yegin A, Ozben T. Serum glycated lipoprotein in type 2 diabetic patients with and without complication. Ann Clin Biochem. 1995;32:459-3.

12. Panteghini M, Cimino A, Pagani F, Girelli A. Nonenzymatic glycation of apolipoprotein B in patients with insulin and non-insulin dependent diabetes mellitus. Clin Biochem. 1995;28:587-2.

13. Freier BM, Sudek CD. Cholesterol in diabetes: the effect of insulin on kenetics of plasms squalene. J Clin Endocrine Metab. 1979;49:824-8.

14. Harno K, Nikkila EA, Kussi T. Metabolism of cholesterol and post heparin plasma hepatic endothelial lipase activity: relationship to obesity and non-insulin dependent diabetes mellitus. Diabetologia. 1980;19:28.

15. Bhalla K, Shukla R, Gupta VP, Puyazhenthi S, Prabhu $\mathrm{K}$ M. Glycosylated proteins and serum lipid profile in complicated and complicated NIDDM patients. Ind J Clin Biochem. 1995;10:57-1.

16. Glomset JA. The plasma lecithin: cholesterol acyl transferase reaction. J Lipid Res. 1968; 9: 155- 67.

17. Yassin HDEL, Hasso NMA, Rubayi HAAL. Lipid profile and lipid peroxidation pattern pre and post exercise in coronary heart disease. Turk J Med Sci. 2005;53:223-8.

18. Goolay A, Zech L, Shi MZ. High density lipoprotein turnover in noninsulin dependent diabetes mellitus. Diabetes. 1985;34:81.

19. Schmitt JK, Poole JR, Lewis SB. Hemoglobin A1 correlates with the ratio of low to high density lipoprotein in normal weight type 2 diabetics. Metabol. 1982;31:1084-9. 